\title{
EMILIN2 Correlated With Its Methylation and Immune Infiltration Could Be an Independent Prognostic Biomarker in LGG
}

\section{Li-chong Wang}

Department of Neurosurgery, The Second Affiliated Hospital of Nanchang University, Nanchang, Jiangxi Province, P.R. China

\section{Zhe Zhang}

Department of Neurosurgery, The Second Affiliated Hospital of Nanchang University, Nanchang, Jiangxi Province, P.R. China

\section{Zi-long Tan}

Department of Neurosurgery, The Second Affiliated Hospital of Nanchang University, Nanchang, Jiangxi Province, P.R. China

\section{Qiao-li Lv}

Department of Head and Neck Surgery, Jiangxi Cancer Hospital, Nanchang, Jiangxi, P.R. China

\section{Shu-hui Chen}

Department of Radiation Oncology, Jiangxi Cancer Hospital, Nanchang, P.R. China

Xiao-Li Shen ( $\square$ shenxldoc@126.com )

second Hospital of Nanchang university https://orcid.org/0000-0001-9541-3462

\section{Research}

Keywords: EMILIN2, methylation, immune, prognostic biomarker, LGG

Posted Date: March 4th, 2021

DOl: https://doi.org/10.21203/rs.3.rs-269510/v1

License: (c) (i) This work is licensed under a Creative Commons Attribution 4.0 International License. Read Full License 


\section{Abstract}

Low-grade gliomas (LGGs) are slow-growing brain cancer in central nervous system neoplasms. EMILIN2 is an extracellular matrix (ECM) protein which could influence the progress of some tumour which is unclear in LGG. In our study, the methylation, expression, prognosis and immune value of EMILIN2 were analysed in LGG through bioinformatics analysis. we first analysed the LGG data from TCGA and discovered that the EMILIN2 expression, negatively correlated to the EMILIN2 methylation could predict a poor prognosis and associated with different clinical parameters. Moreover, univariate and multivariate Cox regression were performed in CGGA showed that the EMILIN2 could be an independent prognostic biomarker in LGG. Finally, EMILIN2 expression showed a correlation with gene makers in some immune cells which identified the significance of EMILIN2 in immune infiltration. In conclusion, EMILIN2 could act as an independent prognostic biomarker which might be associated with the malignancy and development of gliomas and play a crucial role in glioma in immune infiltration.

\section{Introduction}

Low-grade glioma (LGG) is a common primary malignant brain tumour that has great intrinsic heterogeneity in tumour biological behaviour [1]. Grade II and III gliomas, which have a median survival of more than 7 years, are collectively termed diffuse lower-grade gliomas [2-3]. DNA methylation, a major epigenetic modification that has been extensively studied in various cancers, is related to tumour heterogeneity [4]. An increasing number of studies have focused on the association between specific genes and their methylation in tumours, but EMILIN2 has not been studied [5-7].

EMILIN2 was first identified as a $116 \mathrm{kDa}$ extracellular matrix glycoprotein with five protein domains: a Cterminal C1q domain, a proline-rich domain, a collagenous domain, a coiled-coil domain, and an $\mathrm{N}$ terminal cysteine-rich domain (EMI domain) [8-9]. A previous study reported that EMILIN2 could act as a key microenvironmental gene affecting vessel formation [10] or as a tumour suppressor gene in breast cancer. [11] However, there are fewer studies about EMILIN2 in glioma. Meanwhile, the clinical and prognostic value of EMILIN2 expression and methylation in glioma especially in LGG are still unknown.

In the present study, we discovered that EMILIN2 expression in WHO grade III LGG was significantly higher than that in WHO grade II LGG in the Chinese Glioma Genome Atlas (CGGA). Meanwhile, we identified the prognostic role of EMILIN2 for the first time using LGG data from TCGA and the CGGA, which implied that high expression of EMILIN2 could predict a worse prognosis. Moreover, univariate and multivariate Cox regression analyses showed that EMILIN2 was an independent prognostic factor for LGG in the CGGA samples. Then, the correlation between EMILIN2 DNA methylation and EMILIN2 expression and the prognostic significance of EMILIN2 expression were also analysed by using LGG data from TCGA. Additionally, the biological processes of EMILIN2 were analysed by Gene Ontology (GO) and KEGG analysis, which showed that EMILIN2 might have a significant relationship to immunity. Furthermore, the Tumor Immune Estimation Resource (TIMER) database was used to evaluate the potential correlation between EMILIN2 expression and immune infiltration levels and its prognostic value in glioma. Finally, the 
correlation between EMILIN2 and marker genes of immune infiltration was analysed to confirm the vital role of EMILIN2 in immunity.

\section{Materials And Methods}

\section{Microarray Data Processing and Gene Expression Profile Mining}

Then the RNA-seq data and clinical information $(n=1018)$ were downloaded and reanalysed by $R$ from the website (http://www.cgga.org.cn/)[12-15]. we downloaded the clinical and methylated information of glioma $(n=530)$ from TCGA database by the Cbioportal database (https://www.cbioportal.org/) and UCSC-Xena (http://xena.ucsc.edu/).

Gene Ontology and KEGG pathway enrichment analysis

To further study the potential function of EMILIN2, the Gene Ontology (GO) including cellular component (CC), molecular function (MF), and biological process (BP) and Kyoto Encyclopedia of Genes and Genomes (KEGG) pathway were performed by using the R package with EMILIN2 related genes in CGGA which were identified by Pearson test $(R>0.05, p>0.001)$. The $p$-value and $q$-value was no more than 0.05 as a cut-off point.

Immune database analysis

Tumor Immune Estimation Resource (TIMER) database is a web server for comprehensive analysis of tumor-infiltrating immune cells [16-17]. We evaluated the correlation of EMILIN2 expression with the six kinds of immune cells including CD $4+T$ cells, CD8 + T cells, dendritic cells, B cells, neutrophils, and macrophages in LGG and the survival value was also analyzed. Moreover, the spearman coefficient was used in the website to analyse the correlation between EMILIN and the gene markers related immune infiltration including markers of CD8 $+\mathrm{T}$ cells, $\mathrm{T}$ cells (general), B cells, monocytes, tumor-associated macrophage(TAMs), neutrophils, natural killer (NK)cells, M1 macrophages, M2 macrophages, dendritic cells (DCs), T-helper 1 (Th1) cells, T-helper 2(vTh2) cells, T-helper 17 (Th17)cells, Tregs, follicular helper T (Tfh) cells, and exhausted T cells which were reported in previous studies. [18-19]

Statistical analysis

A log-rank test was performed to calculate the difference in overall survival (OS) between high- and lowexpression groups with a median value of the expression or DNA methylation of EMILIN2 as a break point. The expression difference between different clinical features were detected by Wilcoxon text and Kruskal-Wallis text by $\mathrm{R}$ (version 4.0). The univariate and multivariate Cox regression were performed to identify the independent prognostic factors. The relationships between the series clinical factors and EMILIN2 expression or its DNA methylation were analysed by chi-square tests. Pearson correlation coefficient was used to measure the EMILIN2 related genes in CGGA $(R>0.05, p>0.001)$ and the correlation between the EMILIN2 expression and its DNA methylation in TCGA. A p-value of less than 0.05 was considered statistically significant. 


\section{Results}

The clinical and prognostic value of EMILIN2 expression and methylation in glioma

We analysed the expression of EMILIN2 in LGG $(n=528)$ between WHO grade II $(n=258)$ and grade III LGG $(n=270)$ and found that EMILIN2 expression increased markedly with increasing grade level $(P<$ 0.001), as shown in Fig. 1A. To further explore the function of EMILIN2, as shown in Fig. 1B, we observed a obvilously negative correlation $(r=-0.586, P<0.0001)$ between EMILIN2 expression and EMILIN2 DNA methylation. Moreover, the distribution of $29 \mathrm{CpG}$ sites related to EMILIN2 DNA methylation is displayed in Fig. 1C. The analyses of Kaplan-Meier curves showed that high expression (Fig. 1D) or low methylation of EMILIN2 (Fig. 1E) could predict poor overall survival $(\mathrm{OS})(\mathrm{P}<0.001)$.

Additionally, Kaplan-Meier analysis was performed to evaluate the prognostic values of these EMILIN2 DNA CpG sites, and as shown in Fig. 2, these 15 different EMILIN2 DNA CpG sites (cg24276681, cg24948962, cg23405696, cg13765206, cg06769774, cg16181848, cg25813942, cg21266975, cg07483811, cg20679955, cg22349573, cg09009111, cg07012770, cg07431339, cg00093099) were significantly related to prognosis ( $P$ value $<0.05$ ). Next, the patients in TCGA were divided into low or high EMILIN2 expression and EMILIN2 methylation subgroups with the median level as the cut-off value. We applied the chi-square test to detect the detailed relationship of EMILIN2 expression and EMILIN2 methylation with clinical information, which is shown in Table 1. The results showed that EMILIN2 expression was significantly related to age $(P<0.001)$, family history of cancer $(P=0.04)$, IDH mutation $(P=0.003)$, and WHO grade $(P<0.001)$. Meanwhile, the methylation of EMILIN2 was associated with IDH mutation $(P<0.001)$, grade $(P=0.003)$ and KPS $(P=0.021)$. 
Table 1

Correlation between EMILIN2 mRNA expression/methylation and clinical features in TCGA LGG database

\begin{tabular}{|c|c|c|c|c|c|c|c|}
\hline \multirow[t]{2}{*}{ Clinical features } & & \multicolumn{3}{|c|}{ EMILIN2 expression } & \multicolumn{3}{|c|}{ EMILIN2 methylation } \\
\hline & & Low (\%) & High (\%) & $\begin{array}{l}\mathrm{P} \\
\text { value }\end{array}$ & Low (\%) & High (\%) & $\begin{array}{l}\mathrm{P} \\
\text { value }\end{array}$ \\
\hline \multirow[t]{2}{*}{ Age } & $>45$ & 182(68.7) & $143(54.0)$ & \multirow{2}{*}{$\hat{0.001}$} & 153(57.7) & $172(64.9)$ & \multirow[t]{2}{*}{0.09} \\
\hline & $<45$ & 83(31.3) & $122(46.0)$ & & $112(42.3)$ & $93(35.1)$ & \\
\hline \multirow{2}{*}{$\begin{array}{l}\text { Family History } \\
\text { of Cancer }\end{array}$} & No & 118(67.0) & $102(56.7)$ & \multirow[t]{2}{*}{0.04} & $107(60.1)$ & $113(63.5)$ & \multirow[t]{2}{*}{0.513} \\
\hline & Yes & $58(33.0)$ & $78(43.3)$ & & $71(39.9)$ & $65(36.5)$ & \\
\hline \multirow{2}{*}{$\begin{array}{l}\text { Family History } \\
\text { of brain } \\
\text { Cancer }\end{array}$} & No & 175(97.2) & $171(95.0)$ & \multirow[t]{2}{*}{0.276} & $171(94.5)$ & 175(97.8) & \multirow[t]{2}{*}{0.106} \\
\hline & Yes & $5(2.8)$ & $9(5.0)$ & & $10(5.5)$ & $4(2.2)$ & \\
\hline \multirow[t]{2}{*}{ Grade } & II & $148(56.1)$ & $110(41.7 \%)$ & \multirow{2}{*}{$<.001$} & $112(42.4)$ & $146(48.9)$ & \multirow[t]{2}{*}{0.003} \\
\hline & III & $116(43.9)$ & 154(58.3) & & $152(57.6)$ & 118(44.7) & \\
\hline \multirow[t]{2}{*}{ IDH } & No & $9(15.0)$ & $25(38.5)$ & \multirow[t]{2}{*}{0.003} & $27(47.4)$ & $7(10.3)$ & \multirow{2}{*}{$\begin{array}{l}<.001 \\
0.001\end{array}$} \\
\hline & Yes & $51(85.0)$ & $40(61.5)$ & & $30(52.6)$ & $61(89.7)$ & \\
\hline \multirow[t]{2}{*}{$\mathrm{KPS}^{\mathrm{a}}$} & $<80$ & $57(27.4)$ & $74(35.4)$ & \multirow[t]{2}{*}{0.078} & $76(36.7)$ & $55(26.2)$ & \multirow[t]{2}{*}{0.02} \\
\hline & $>80$ & 151(72.6) & $135(64.6)$ & & $131(63.6)$ & $155(73.8)$ & \\
\hline \multirow[t]{2}{*}{ Sample type } & Primary & $260(98.1)$ & $260(98.1)$ & \multirow[t]{2}{*}{0.279} & $260(98.1)$ & $260(98.1)$ & \multirow[t]{2}{*}{0.279} \\
\hline & recurrence & $5(1.9)$ & $9(3.4)$ & & $9(3.4)$ & $5(1.9)$ & \\
\hline \multirow[t]{2}{*}{ Seizure } & No & $94(38.7)$ & $89(35.5)$ & \multirow[t]{2}{*}{0.458} & $87(35.4)$ & $96(38.7)$ & \multirow[t]{2}{*}{0.44} \\
\hline & Yes & $149(61.3)$ & $162(64.5)$ & & 159(64.6) & $152(61.3)$ & \\
\hline \multirow[t]{2}{*}{ Sex } & Female & $123(46.6)$ & $115(43.4)$ & \multirow[t]{2}{*}{0.460} & $126(47.5)$ & $112(42.4)$ & \multirow[t]{2}{*}{0.236} \\
\hline & male & $141(53.4)$ & $150(56.6)$ & & $139(52.5)$ & $152(57.6)$ & \\
\hline
\end{tabular}

${ }^{a}$ KPS represents karnofsky performance status.

Identification of the prognostic and clinical value of EMILIN2 in LGG from CGGA by bioinformatic analysis

We downloaded RNA-seq data and clinical information for 1008 patients from CGGA to further verify the prognostic significance of EMILIN2. As shown in Fig. 3A-F, the mRNA expression of EMILIN2 was 
significantly associated with clinical information in groups divided by histology $(P<0.001)$, cancer type $(P<0.001)$, WHO grade $(P<0.001)$, MGMT mutation $(P=0.045)$, 1p19q codeletion $(P<0.001)$ and IDH1 mutation $(P<0.001)$. There was no association found to be related to EMILIN2 mRNA expression in age, chemotherapy status, radio treatment, or sex $(P>0.05)$. These results showed that the expression of EMILIN2 was strongly related to the clinical parameters. In addition, we performed Kaplan-Meier analysis to confirm the prognostic value of EMILIN2, which showed that high EMILIN2 expression predicted poor OS (Fig. 3G).

\section{EMILIN2 could be an independent prognostic biomarker in LGG}

The above results indicated that the expression of EMILIN2 was closely associated with OS. To further verify the independent prognostic significance of EMILIN2, we further analysed the LGG patient data from the CGGA database by univariate and multivariate Cox regression analysis. As shown in the forest diagram (Fig. 4A-B), EMILIN2 could be an independent prognostic biomarker $(p=0.018$, hazard ratio $=$ $1.180(1.029-1.354))$. The primary and recurrent status (PRS) $(p=0.005$, hazard ratio $=4.197(1.532-$ 11.495)), WHO grade $(P<0.001$, hazard ratio $=2.492(1.769-3.510))$, and $1 p 19 q$ codeletion $(P=0.002$, hazard ratio $=0.432(0.253-0.739))$ might also be independent prognostic factors in CGGA.

\section{EMILIN2-related Gene Ontology and signalling pathways in gliomas.}

To evaluate the function of EMILIN2 in glioma, we performed Pearson's test to identify EMILIN2coexpressed genes in LGG from the CGGA. There were 924 genes that were related to the expression of EMILIN2 with a p-value $<0.01$ and $R>0.5$ as cut-off points. Then, we performed $\mathrm{GO}$ and Kyoto Encyclopedia of Genes and Genomes (KEGG) analyses to detect the functions of the EMILIN2-correlated genes. Figure 4C-D showed the top ten most enriched biological process (BP), cellular component (CC), and molecular function (MF) terms and the top thirty most enriched KEGG pathways among the DEGs. The EMILIN2-correlated genes were involved in T cell activation, regulation of $T$ cell activation, neutrophil activation involved in the immune response, growth factor binding, immune receptor activity, human $T$ cell leukaemia virus 1 infection, Th1 and Th2 cell differentiation, and the Th17 cell differentiation signalling pathway. Based on these terms, we found that abnormal expression of EMILIN2 might lead to immune system changes in glioma.

The expression of EMILIN2 was correlated with tumour immune infiltration and related markers in glioma The TIMER database was used to analyse the correlations between EMILIN2 expression and immune cell infiltration. The expression of EMILIN2 was positively correlated with B cell $(r=0.391, P<0.001), C D 8+T$ cell $(r=0.275, P<0.001), C D 4+T$ cell $(r=0.417, P<0.001)$, dendritic cell $(r=0.492, P<0.001)$, macrophage $(r=0.51, P<0.001)$ and neutrophil $(r=0.435, P<0.001)$ infiltration and was negatively correlated with tumour purity $(r=-0.279, P<0.001)$ in LGG. Moreover, we also explored the prognostic value of EMILIN2 in LGG with different abundances of immune cells. The results showed that highexpressed EMILIN2 was significantly associated with the bad prognosis, as shown in Fig. 5, in different abundances of immune cells. The Cox proportional hazard model built in the TIMER database, as shown in Table 2, showed that EMILIN2 expression was an independent prognostic marker of LGG prognosis. 
Table 2

The cox proportional Hazard Model in different immune cells and EMILIN2

\begin{tabular}{|llllll|}
\hline & Coef & HR & $95 \% \mathrm{Cl}-\mathrm{L}$ & $95 \% \mathrm{Cl}-\mathrm{U}$ & P value \\
\hline Purity & 0.411 & 1.508 & 0.559 & 4.069 & 0.417 \\
\hline B_cell & 0.775 & 2.172 & 0.005 & 1034.743 & 0.805 \\
\hline CD8_T cell & 7.037 & 1137.874 & 0.952 & 1359400.899 & 0.052 \\
\hline CD4_T cell & -0.641 & 0.527 & 0.000 & 1700.333 & 0.876 \\
\hline Macrophage & 4.744 & 114.859 & 1.474 & 8947.663 & 0.033 \\
\hline Neutrophil & -3.475 & 0.031 & 0.000 & 70.929 & 0.379 \\
\hline Dendritic & 0.388 & 1.474 & 0.021 & 103.170 & 0.858 \\
\hline EMILIN2 & 0.275 & 1.316 & 1.097 & 1.579 & 0.003 \\
\hline
\end{tabular}

Additionally, as shown in Table,3 we analysed the correlations between EMILIN2 expression and many immune markers of various immune cells, including CD $8+T$ cells, $T$ cells(general), the different functional T cells, such as Th1 cells, Th2 cells, Tfh cells, Th17 cells, and Tregs, as well as exhausted T cells, NK cells, B cells, monocytes, M1 and M2 macrophages, neutrophils, TAMs, and Dendritic cell in LGG. The result showed that most of the markers were strongly related to EMILIN2 expression, regardless of whether the data were adjusted by tumour purity. 
Table 3

Correlation analysis between EMILIN2 and related genes of immune cells in TIMER.

\begin{tabular}{|c|c|c|c|c|c|}
\hline \multirow[t]{3}{*}{ Description } & \multirow[t]{3}{*}{ Gene markers } & \multicolumn{4}{|l|}{ LGG } \\
\hline & & \multicolumn{2}{|l|}{ None } & \multicolumn{2}{|l|}{ Purity } \\
\hline & & Cor & P-Value & Cor & $P$ \\
\hline \multirow[t]{2}{*}{ CD8 $+\mathrm{T}$ cell } & CD8A & 0.431 & $\star \star \star *$ & 0.381 & $\star \star \star$ \\
\hline & CD8B & 0.427 & $* * *$ & 0.388 & $\star * *$ \\
\hline \multirow[t]{3}{*}{ T cell (general) } & CD3D & 0.58 & $* * *$ & 0.555 & $* \star *$ \\
\hline & CD3E & 0.614 & $\star \star * *$ & 0.603 & $\star * *$ \\
\hline & $\mathrm{CD} 2$ & 0.607 & $\star \star \star *$ & 0.595 & $\star \star * *$ \\
\hline \multirow[t]{2}{*}{ B cell } & CD19 & 0.383 & $\star \star \star *$ & 0.332 & $\star \star \star *$ \\
\hline & CD79A & 0.165 & $\star \star \star *$ & 0.175 & $\star \star \star *$ \\
\hline \multirow[t]{2}{*}{ Monocyte } & CD86 & 0.425 & $\star \star \star *$ & 0.352 & $\star \star \star *$ \\
\hline & CD115:CSF1R & 0.25 & $\star \star \star *$ & 0.137 & 0.00260 \\
\hline \multirow[t]{3}{*}{ TAM } & CCL2 & 0.379 & $\star \star \star *$ & 0.342 & $\star \star \star *$ \\
\hline & CD68 & 0.494 & $\star \star * *$ & 0.452 & $\star \star \star *$ \\
\hline & IL10 & 0.395 & $* * *$ & 0.354 & $\star \star \star$ \\
\hline \multirow[t]{3}{*}{ M1 Macrophage } & INOS(NOS2) & -0.027 & 0.54 & -0.038 & 0.404 \\
\hline & IRF5 & 0.423 & $\star \star *$ & 0.353 & $* * *$ \\
\hline & $\mathrm{cox} 2$ & 0.152 & $\star \star * *$ & 0.098 & 0.033 \\
\hline \multirow[t]{3}{*}{ M2 Macrophage } & CD163 & 0.385 & $\star \star * *$ & 0.33 & $\star * *$ \\
\hline & VSIG4 & 0.277 & $\star \star \star *$ & 0.205 & $\star \star \star$ \\
\hline & MS4A4A & 0.386 & $\star \star \star *$ & 0.368 & $\star \star \star$ \\
\hline \multirow[t]{3}{*}{ Neutrophils } & CD66b (CEACAM8) & -0.014 & 0.745 & -0.016 & 0.724 \\
\hline & CD11b (ITGAM) & 0.363 & $\star \star \star \star ~$ & 0.272 & $\star \star \star$ \\
\hline & CCR7 & 0.537 & $\star \star \star$ & 0.549 & $\star \star \star$ \\
\hline \multirow[t]{4}{*}{ Natural killer cell } & KIR2DL1 & 0.051 & 0.249 & 0.068 & 0.139 \\
\hline & KIR2DL3 & 0.238 & $\star \star \star *$ & 0.234 & $\star \star \star ~$ \\
\hline & KIR2DL4 & 0.24 & $\star \star \star ~$ & 0.229 & $\star \star \star ~$ \\
\hline & KIR3DL1 & 0.096 & 0.0285 & 0.081 & 0.0768 \\
\hline
\end{tabular}




\begin{tabular}{|c|c|c|c|c|c|}
\hline & KIR3DL2 & 0.188 & $\star \star * *$ & 0.186 & $\star \star \star *$ \\
\hline & KIR3DL3 & -0.041 & 0.355 & -0.059 & 0.197 \\
\hline & KIR2DS4 & 0.173 & $\star \star *$ & 0.167 & $\star \star \star$ \\
\hline \multirow[t]{7}{*}{ Dendritic cell } & HLA-DPB1 & 0.581 & $\star \star \star *$ & 0.541 & $\star \star \star ~$ \\
\hline & HLA-DQB1 & 0.492 & $\star \star \star$ & 0.453 & $\star \star \star$ \\
\hline & HLA-DRA & 0.567 & $\star \star \star$ & 0.523 & $\star \star \star ~$ \\
\hline & HLA-DPA1 & 0.569 & $\star \star \star$ & 0.531 & $\star \star \star$ \\
\hline & BDCA-1(CD1C) & 0.358 & $\star \star *$ & 0.346 & $\star \star \star ~$ \\
\hline & BDCA-4(NRP1) & 0.405 & $\star * \star$ & 0.45 & $\star \star \star *$ \\
\hline & CD11c (ITGAX) & 0.48 & $\star \star \star$ & 0.422 & $\star \star \star *$ \\
\hline \multirow[t]{5}{*}{ Th1 } & T-bet (TBX21 & 0.436 & $\star \star \star$ & 0.455 & $\star \star \star$ \\
\hline & STAT4 & 0.07 & 0.11 & 0.028 & 0.545 \\
\hline & STAT1 & 0.432 & $\star \star \star$ & 0.426 & $\star \star \star ~$ \\
\hline & TNF- a(TNF) & 0.084 & 0.0578 & 0.037 & 0.422 \\
\hline & IFN-y (IFNG) & 0.281 & $\star \star \star *$ & 0.258 & $\star \star \star ~$ \\
\hline \multirow[t]{4}{*}{ Th2 } & GATA3 & 0.386 & $\star \star \star ~$ & 0.359 & $\star \star \star ~$ \\
\hline & STAT6 & 0.435 & $\star \star \star$ & 0.365 & $\star \star \star$ \\
\hline & STAT5A & 0.53 & $\star \star \star *$ & 0.47 & $\star \star \star *$ \\
\hline & IL13 & -0.021 & 0.628 & -0.013 & 0.770 \\
\hline \multirow[t]{2}{*}{ Tfh } & BCL6 & -0.157 & $\star \star \star ~$ & -0.144 & 0.00157 \\
\hline & IL21 & 0.103 & 0.0192 & 0.088 & 0.0552 \\
\hline \multirow[t]{2}{*}{ Th17 } & STAT3 & 0.391 & $\star \star \star *$ & 0.391 & $\star \star \star ~$ \\
\hline & IL17A & -0.04 & 0.366 & -0.056 & 0.218 \\
\hline \multirow[t]{4}{*}{ Treg } & CCR8 & 0.281 & $\star \star \star *$ & 0.293 & $\star \star \star ~$ \\
\hline & STAT5B & -0.171 & $\star \star \star$ & -0.102 & 0.0262 \\
\hline & FOXP3 & 0.036 & 0.409 & 0.072 & 0.118 \\
\hline & TGF- $\beta$ (TGFB1) & 0.387 & $\star \star \star$ & 0.313 & $\star \star \star ~$ \\
\hline \multirow[t]{2}{*}{ T cell exhaustion } & PD-1 (PDCD1) & 0.516 & $\star \star \star$ & 0.496 & $\star \star \star ~$ \\
\hline & CTLA4 & 0.397 & $\star \star *$ & 0.35 & $\star \star \star *$ \\
\hline
\end{tabular}




\begin{tabular}{|c|c|c|c|c|c|}
\hline & LAG3 & 0.187 & 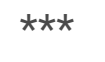 & 0.22 & $\star \star \star$ \\
\hline & TIM-3 (HAVCR2) & 0.478 & $\star \star \star \star ~$ & 0.416 & $\star \star \star \star ~$ \\
\hline & GZMB & 0.369 & 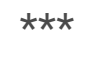 & 0.384 & $\star \star \star$ \\
\hline$\star \star \star * P<0.001$ & & & & & \\
\hline
\end{tabular}

\section{Discussion/conclusion}

Currently, an increasing number of studies are focused on using bioinformatics analyses of previously published data to identify factors that play a vital role in various cancers. In our previous study, we found that the expression of EMILIN2 increased with increasing LGG grade. A previous study identified that EMILIN2 could play an important role in angiogenesis, platelet activation, thrombus formation, clot retraction and breast cancer $[10-11,18]$. However, few studies have examined the function of EMILIN2 in glioma, especially in LGG.

In the present study, we first discovered that EMILIN2 is more highly expressed in WHO grade III compared to grade II LGG in the data from TCGA and the CGGA, which revealed that the altered expression of EMILIN2 might significantly regulate the progression of LGG. Similar results were found for EMILIN2 expression in gastric tumours and ovarian serous tumours [19-21].

Moreover, we analysed the correlation between EMILIN2 expression and methylation and found that the expression of EMILIN2 was negatively associated with EMILIN2 methylation in LGG. EMILIN2 hypermethylation and low expression also predicted good OS in LGG. Then, the prognostic and clinical value of EMILIN2 was identified based LGG from the CGGA database, which was similar to the findings from the TGGA database in terms of IDH, WHO grades and OS. We further identified the prognostic value of EMILIN2 DNA methylation. Almost all sites were significantly related to OS, which verified the prognostic relevance of EMILIN2. Many studies have indicated that the relationship between specific DNA methylation sites and the expression of neighbouring genes ranges from weak to moderate, and there are few genes that are regulated by DNA methylation $[1,5-7]$. In our study, we found that EMILIN2 was obviously and negatively regulated by its DNA methylation. EMILIN2 methylation status and its expression might be a potent biomarker of OS. A similar result was found in breast cancer [22]. Similarly, the prognostic value of EMILIN2 has been reported in lung adenocarcinoma [23].

Furthermore, the LGG database from CGGA was used to reconfirm the prognostic and clinical value of EMILIN2 and showed a similar result: the expression of EMILIN2 was remarkably associated with clinical parameters such as histology, WHO grade, IDH1 mutation and even survival status. Moreover, univariate and multivariate Cox regression analyses were performed, and the results showed that EMILIN2 could be an independent prognostic biomarker $(p=0.018$, hazard ratio $=1.180(1.029-1.354))$; PRS type, WHO grade, and 1p19q_codeletion could also be independent prognostic factors in LGG. Furthermore, we performed GO and KEGG analyses to reveal the function of EMILIN2 in CGGA. The results implied that EMILIN2 might be involved in immune-related biological functions. 
A lot of studies have found that tumour-infiltrating immune cells play an important role in the progression and development of cancer [24-27]. Few studies have pointed out the relationship between EMILIN2 and immune infiltration. Therefore, the TIMER database was used to detect the relationship between immune infiltration and EMILIN2 expression. In our study, our results first revealed that the levels of immune infiltration were significantly correlated with EMILIN2 expression in LGG. Furthermore, we observed that EMILIN2 expression was positively correlated with B cells in LGG. Additionally, EMILIN2 was significantly associated with OS at different levels of immune infiltration, which again suggested the prognostic significance of EMILIN2 in LGG.

Additionally, the correlation between EMILIN2 expression and the markers of immune cells indicated that EMILIN2 might regulate tumour immunology in LGG. Studies have reported a positive correlation between elevated CD8 + T cells in the tumour microenvironment (TME) and good prognosis in cancer [28]. The gene markers of CD8 $+T$ cells, $T$ cells (general), and $B$ cells such as CD8A, CD8B, CD3D, CD3E, CD2, CD19, CD79A, CD86, and CD115 showed significantly positive correlations with EMILIN2 expression, which verified the prognostic and immune value of EMILIN2. Macrophages play an important role in maintaining tissue homeostasis and modulating the immune response against pathogens as scavengers [29]. Thus, we detected correlations between biomarkers of $M 1$ and $M 2$ macrophages and tumourassociated macrophages (TAMs), revealing the potential regulatory function of EMILIN2 in macrophages. In addition, our results shown in the Table 3 indicated that EMILIN2 could activate Tregs and induce T cell exhaustion. Moreover, helper T cells were reported to have the strongest relationship with clinical outcome in early-stage vulvar cancer [30]. Our study showed that there were many significant correlations between EMILIN2 expression and various markers of T helper cells (Th1, Th2, Tfh, and Th17) in LGG, which indicated that EMILIN2 might regulate T cell functions and influence the clinical outcome in LGG. EMILIN2 expression negatively correlated with that of STAT5B, an important role in the maintenance of normal immune function and homeostasis [31], but positively correlated with the expression of Treg and T cell exhaustion markers (CCR8, FOXP3, TGF- $\beta$ (TGFB1), PD-1, CTLA4, LAG3, GZMB, and TIM-3) in LGG. These results suggest that EMILIN2 plays a vital role in the regulation of immune infiltrating cells in LGG. However, additional experiments to identify the potential mechanisms of EMILIN2 are urgently needed in the future.

In summary, EMILIN2 expression negatively correlated with EMILIN2 methylation, potentially contributes to the regulation of immune infiltration and is a potential biomarker of OS in LGG.

\section{Declarations}

\section{Ethics approval and consent to participate}

This article didn't need the Ethics approval and consent.

\section{Consent for publication}

All authors approved the publication. 
Competing interests

We declared that there is no interest conflict.

\section{Funding}

This study was supported in part by grants from The National Natural Science Foundation of China (No. 81860664, 81960458, 82060680) and Technology Research Project of Jiangxi Provincial Department of Education (180077). Clinical Research Projects (2014YNLC12009).

\section{Authors' contributions}

L-C W and ZZ conceived and wrote the manuscript. L-C W and ZZ participated in data analysis. Q-L L, S-H $C$, and Z-L T participated in discussion and language editing. X-L $S$ reviewed the manuscript.

\section{Availability of data and material}

All datasets generated for this study are included in the Article and available in the online website.

\section{Acknowledgement}

Thanks to all authors for their contributions to this article.

\section{References}

1. Tan Y, Zhang S, Xiao Q, Wang J, Zhao K, Liu W, Huang K, Tian W, Niu H, Lei T et al: Prognostic significance of ARL9 and its methylation in low-grade glioma. Genomics 2020, 112(6):4808-4816.

2. Ostrom QT, Gittleman H, Fulop J, Liu M, Blanda R, Kromer C, Wolinsky Y, Kruchko C, Barnholtz-Sloan JS: CBTRUS Statistical Report: Primary Brain and Central Nervous System Tumors Diagnosed in the United States in 2008-2012. Neuro-oncology 2015, 17 Suppl 4(Suppl 4):iv1-iv62.

3. Aoki K, Nakamura H, Suzuki H, Matsuo K, Kataoka K, Shimamura T, Motomura K, Ohka F, Shiina S, Yamamoto $\mathrm{T}$ et al: Prognostic relevance of genetic alterations in diffuse lower-grade gliomas. Neurooncology 2018, 20(1):66-77.

4. Hansen KD, Timp W, Bravo HC, Sabunciyan S, Langmead B, McDonald OG, Wen B, Wu H, Liu Y, Diep $\mathrm{D}$ et al: Increased methylation variation in epigenetic domains across cancer types. Nature genetics 2011, 43(8):768-775.

5. Zhang $H$, Zhang L, Tang $Y$, Wang $C$, Chen $Y$, Shu J, Zhang K: Systemic screening identifies GABRD, a subunit gene of GABAA receptor as a prognostic marker in adult IDH wild-type diffuse low-grade glioma. Biomedicine \& pharmacotherapy = Biomedecine \& pharmacotherapie 2019, 118:109215.

6. Wang Z, Wang Z, Zhang C, Liu X, Li G, Liu S, Sun L, Liang J, Hu H, Liu Y et al: Genetic and clinical characterization of B7-H3 (CD276) expression and epigenetic regulation in diffuse brain glioma. Cancer science 2018, 109(9):2697-2705. 
7. Ma X, Shang F, Zhu W, Lin Q: CXCR4 expression varies significantly among different subtypes of glioblastoma multiforme (GBM) and its low expression or hypermethylation might predict favorable overall survival. Expert review of neurotherapeutics 2017, 17(9):941-946.

8. Colombatti A, Doliana R, Bot S, Canton A, Mongiat M, Mungiguerra G, Paron-Cilli S, Spessotto P: The EMILIN protein family. Matrix biology : journal of the International Society for Matrix Biology 2000, 19(4):289-301.

9. Bressan GM, Daga-Gordini D, Colombatti A, Castellani I, Marigo V, Volpin D: Emilin, a component of elastic fibers preferentially located at the elastin-microfibrils interface. The Journal of cell biology 1993, 121(1):201-212.

10. Paulitti A, Andreuzzi E, Bizzotto D, Pellicani R, Tarticchio G, Marastoni S, Pastrello C, Jurisica I, Ligresti G, Bucciotti $F$ et al: The ablation of the matricellular protein EMILIN2 causes defective vascularization due to impaired EGFR-dependent IL-8 production affecting tumor growth. Oncogene 2018, 37(25):3399-3414.

11. Marastoni S, Andreuzzi E, Paulitti A, Colladel R, Pellicani R, Todaro F, Schiavinato A, Bonaldo P, Colombatti $A$, Mongiat M: EMILIN2 down-modulates the Wnt signalling pathway and suppresses breast cancer cell growth and migration. The Journal of pathology 2014, 232(4):391-404.

12. Wang Y, Qian T, You G, Peng X, Chen C, You Y, Yao K, Wu C, Ma J, Sha Z et al: Localizing seizuresusceptible brain regions associated with low-grade gliomas using voxel-based lesion-symptom mapping. Neuro-oncology 2015, 17(2):282-288.

13. Liu X, Li Y, Qian Z, Sun Z, Xu K, Wang K, Liu S, Fan X, Li S, Zhang Z et al: A radiomic signature as a non-invasive predictor of progression-free survival in patients with lower-grade gliomas. Neurolmage Clinical 2018, 20:1070-1077.

14. Bao ZS, Chen HM, Yang MY, Zhang CB, Yu K, Ye WL, Hu BQ, Yan W, Zhang W, Akers J et al: RNA-seq of 272 gliomas revealed a novel, recurrent PTPRZ1-MET fusion transcript in secondary glioblastomas. Genome research 2014, 24(11):1765-1773.

15. Zhao Z, Meng F, Wang W, Wang Z, Zhang C, Jiang T: Comprehensive RNA-seq transcriptomic profiling in the malignant progression of gliomas. Scientific data 2017, 4:170024.

16. Li T, Fan J, Wang B, Traugh N, Chen Q, Liu JS, Li B, Liu XS: TIMER: A Web Server for Comprehensive Analysis of Tumor-Infiltrating Immune Cells. Cancer research 2017, 77(21):e108-e110.

17. Li B, Severson E, Pignon JC, Zhao H, Li T, Novak J, Jiang P, Shen H, Aster JC, Rodig S et al: Comprehensive analyses of tumor immunity: implications for cancer immunotherapy. Genome biology 2016, 17(1):174.

18. Huang $M$, Sannaningaiah $D$, Zhao N, Gong Y, Grondolsky J, Hoover-Plow J: EMILIN2 regulates platelet activation, thrombus formation, and clot retraction. PloS one 2015, 10(2):e0115284.

19. Andreuzzi E, Capuano A, Pellicani R, Poletto E, Doliana R, Maiero S, Fornasarig M, Magris R, Colombatti A, Cannizzaro R et al: Loss of Multimerin-2 and EMILIN-2 Expression in Gastric Cancer Associate with Altered Angiogenesis. International journal of molecular sciences 2018, 19(12). 
20. Salani R, Neuberger I, Kurman RJ, Bristow RE, Chang HW, Wang TL, Shih le M: Expression of extracellular matrix proteins in ovarian serous tumors. International journal of gynecological pathology : official journal of the International Society of Gynecological Pathologists 2007, 26(2):141-146.

21. Scholler N, Gross JA, Garvik B, Wells L, Liu Y, Loch CM, Ramirez AB, McIntosh MW, Lampe PD, Urban $\mathrm{N}$ : Use of cancer-specific yeast-secreted in vivo biotinylated recombinant antibodies for serum biomarker discovery. Journal of translational medicine 2008, 6:41.

22. Hill VK, Hesson LB, Dansranjavin T, Dallol A, Bieche I, Vacher S, Tommasi S, Dobbins T, Gentle D, Euhus $\mathrm{D}$ et al: Identification of $\mathbf{5}$ novel genes methylated in breast and other epithelial cancers. Molecular cancer 2010, 9:51.

23. Tessema M, Yingling CM, Liu Y, Tellez CS, Van Neste L, Baylin SS, Belinsky SA: Genome-wide unmasking of epigenetically silenced genes in lung adenocarcinoma from smokers and never smokers. Carcinogenesis 2014, 35(6):1248-1257.

24. Guo X, Pan Y, Xiong M, Sanapala S, Anastasaki C, Cobb O, Dahiya S, Gutmann DH: Midkine activation of CD8(+) T cells establishes a neuron-immune-cancer axis responsible for low-grade glioma growth. Nature communications 2020, 11(1):2177.

25. Zhang M, Wang X, Chen X, Zhang Q, Hong J: Novel Immune-Related Gene Signature for Risk Stratification and Prognosis of Survival in Lower-Grade Glioma. Frontiers in genetics 2020, 11:363.

26. Weenink B, Draaisma K, Ooi HZ, Kros JM, Sillevis Smitt PAE, Debets R, French PJ: Low-grade glioma harbors few CD8 T cells, which is accompanied by decreased expression of chemo-attractants, not immunogenic antigens. Scientific reports 2019, 9(1):14643.

27. Wu F, Li GZ, Liu HJ, Zhao Z, Chai RC, Liu YQ, Jiang HY, Zhai Y, Feng YM, Li RP et al: Molecular subtyping reveals immune alterations in IDH wild-type lower-grade diffuse glioma. The Journal of pathology 2020, 251(3):272-283.

28. Maimela NR, Liu S, Zhang Y: Fates of CD8+ T cells in Tumor Microenvironment. Computational and structural biotechnology journal2019, 17:1-13.

29. Mehla K, Singh PK: Metabolic Regulation of Macrophage Polarization in Cancer. Trends in cancer 2019, 5(12):822-834.

30. Kortekaas KE, Santegoets SJ, Abdulrahman Z, van Ham VJ, van der Tol M, Ehsan I, van Doorn HC, Bosse T, van Poelgeest MIE, van der Burg SH: High numbers of activated helper T cells are associated with better clinical outcome in early stage vulvar cancer, irrespective of HPV or p53 status. Journal for immunotherapy of cancer 2019, 7(1):236.

31. Rani A, Murphy JJ: STAT5 in Cancer and Immunity. Journal of interferon \& cytokine research : the official journal of the International Society for Interferon and Cytokine Research 2016, 36(4):226-237.

\section{Figures}


$\mathrm{B}$
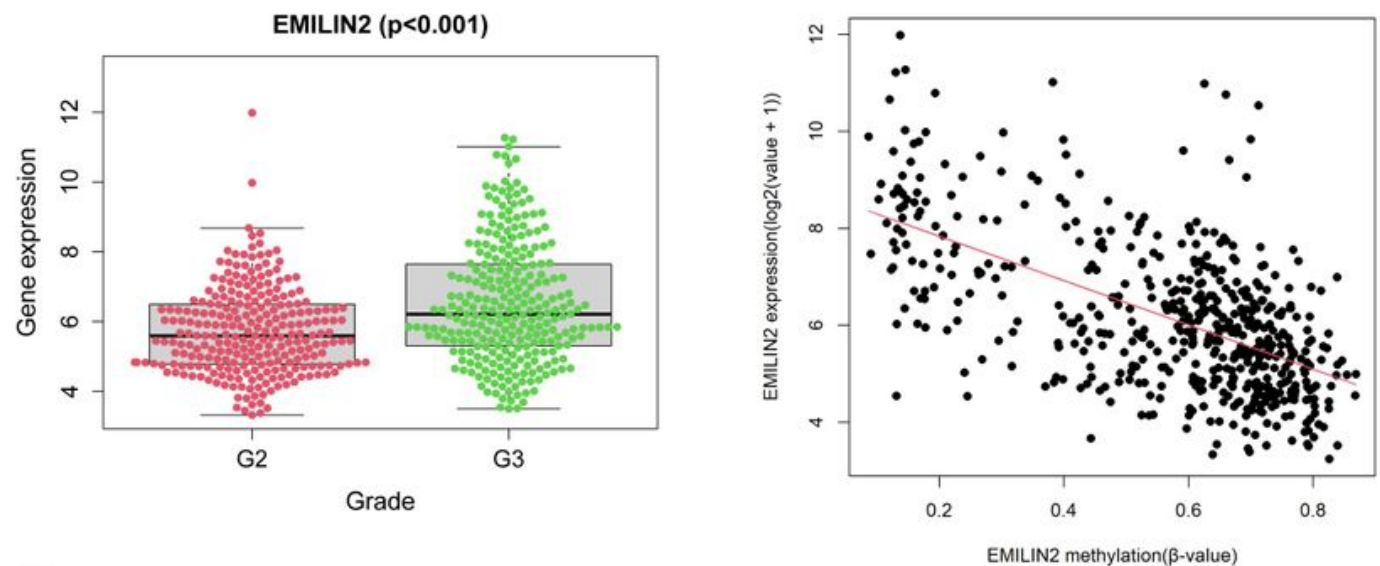

$\mathrm{C}$

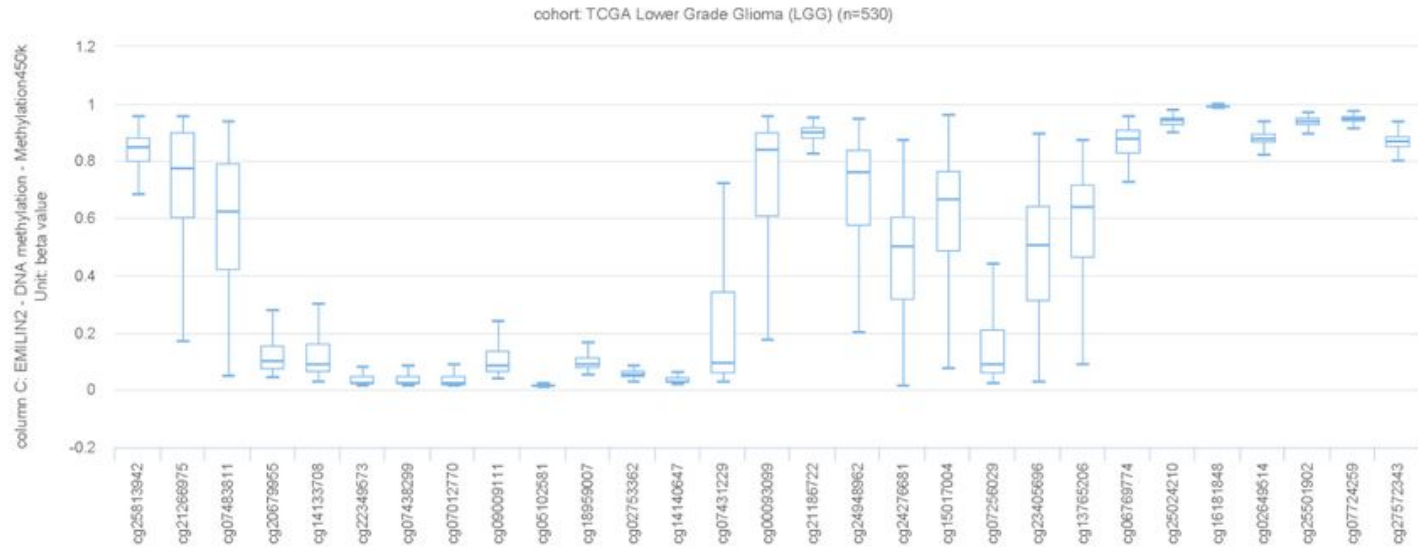

$\mathrm{D}$

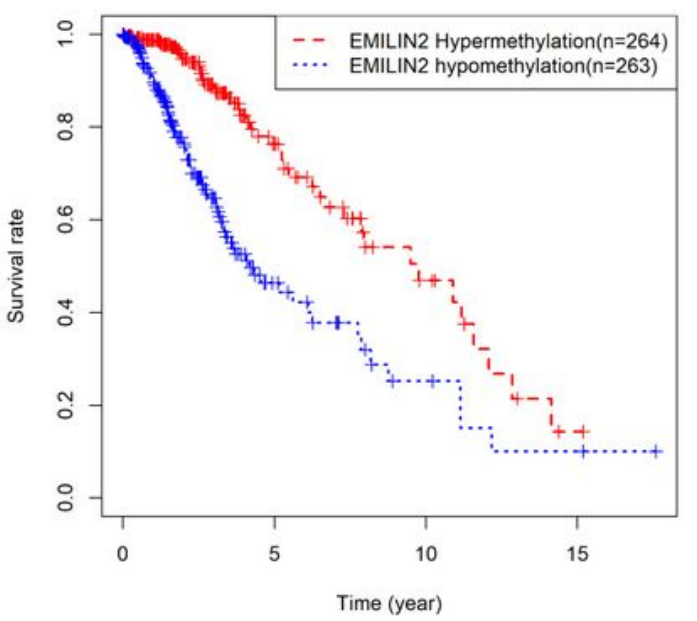

$\mathrm{E}$

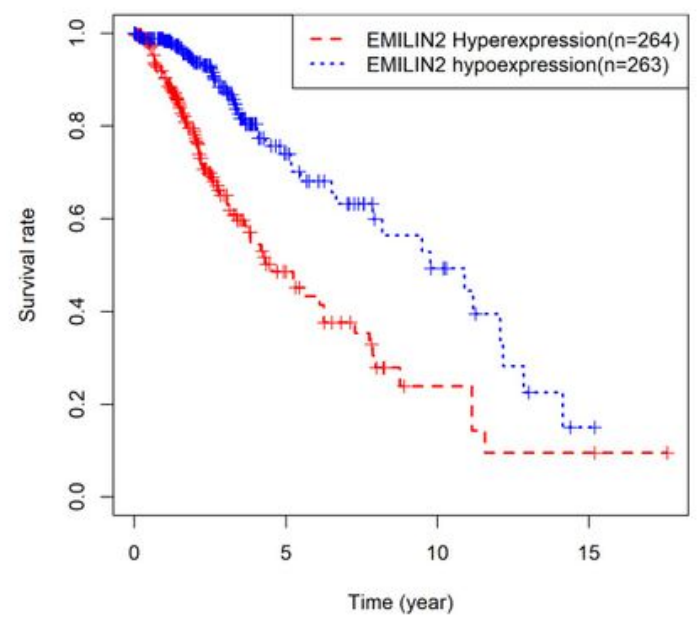

\section{Figure 1}

A The expression, methylation and prognostic value of EMILIN2 in LGG tissues from TCGA. (A) The differently expressed in different WHO grades in LGG. (B) EMILIN2 expression was negatively correlated with EMILIN2 DNA methylation. (C) The distribution of 29 EMILIN2 promoter CpG sites. (D-E) KaplanMeier survival curves of the EMILIN2 expression and DNA methylation in LGG from TCGA. 

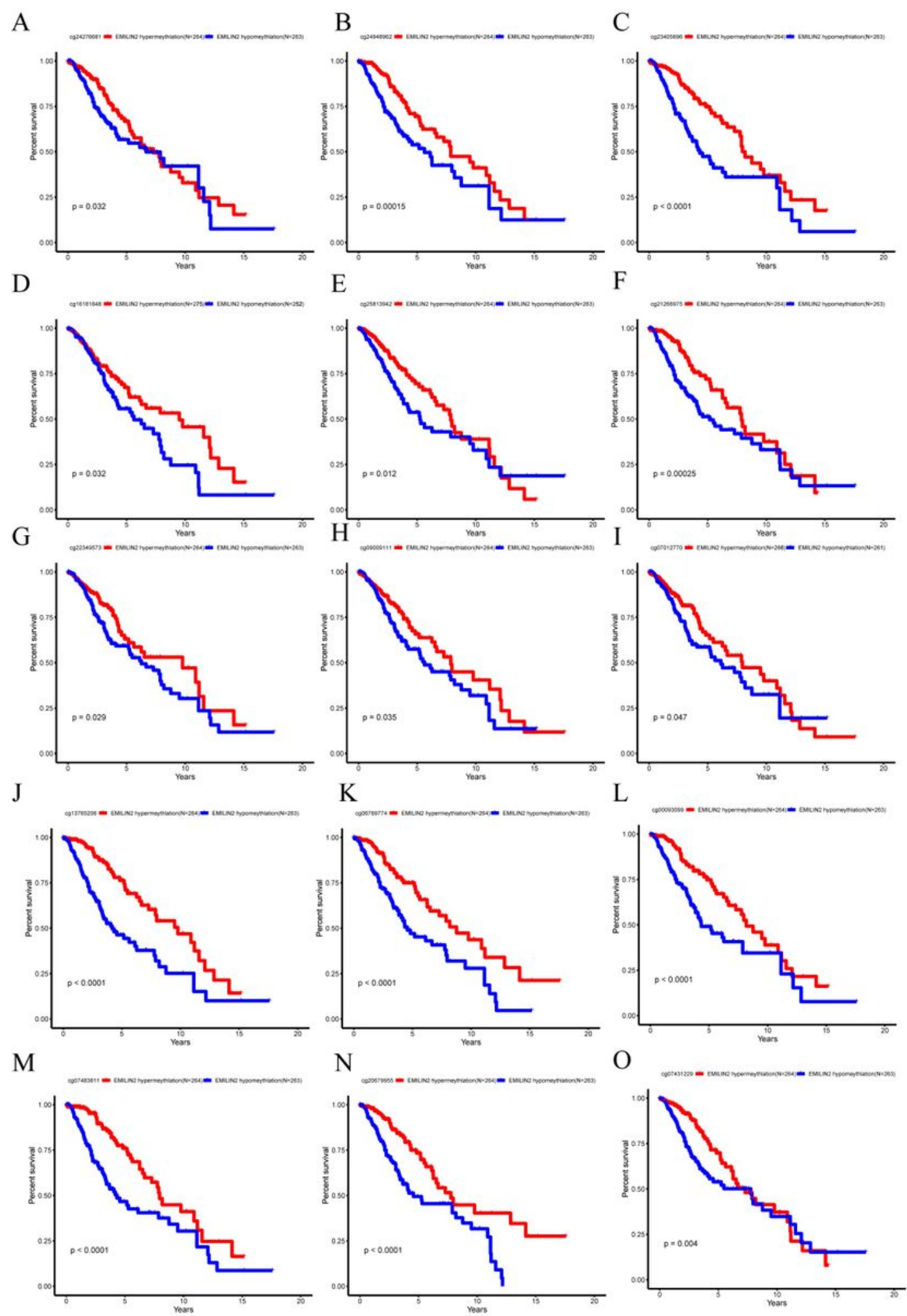

Figure 2

Kaplan-Meier curves of low and high EMILIN2 DNA methylation in 15 promoter CpG sites in LGG patients 

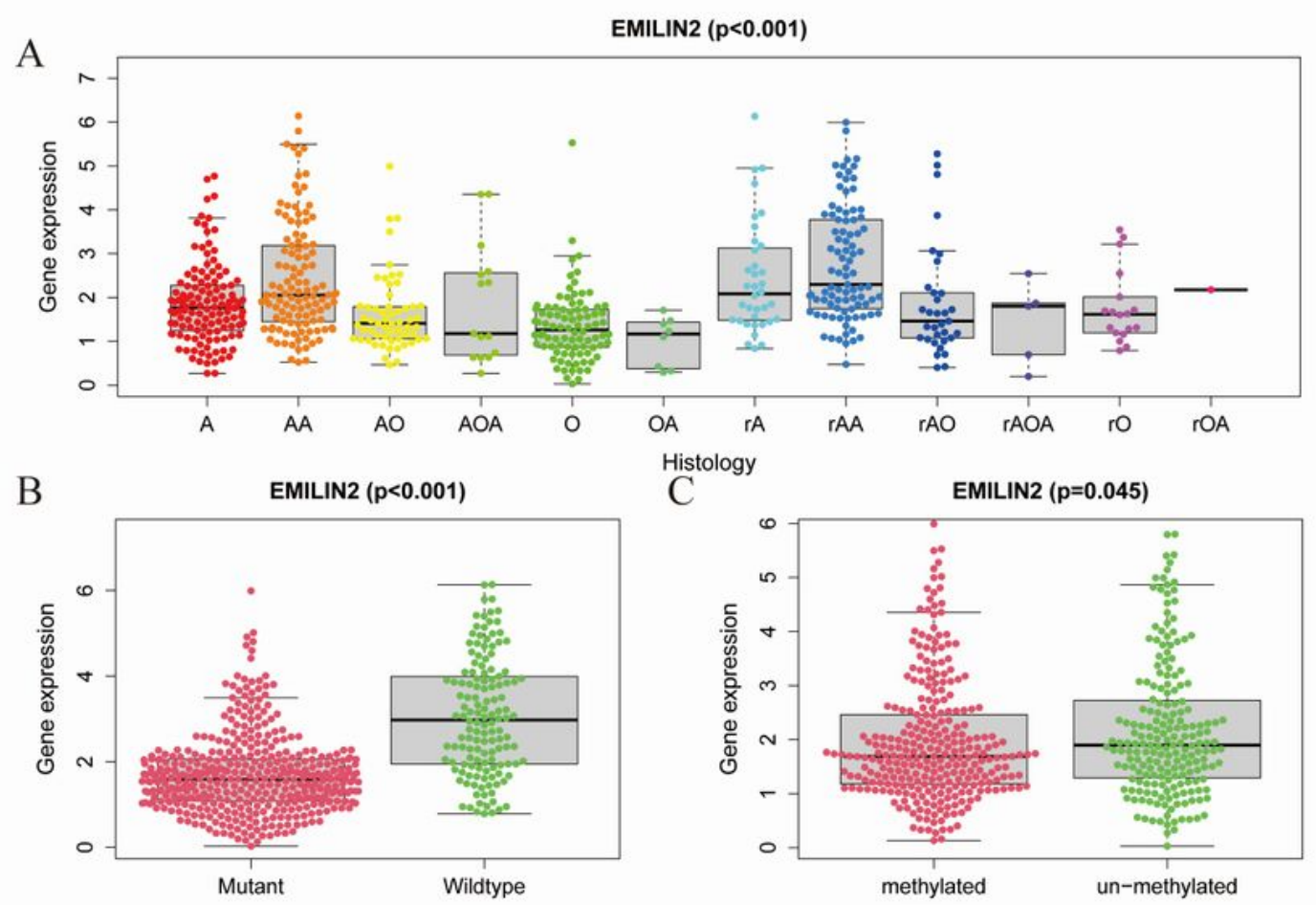

$\mathrm{C}^{\text {Histology }}$ EMILIN2 $(p=0.045)$

$\mathrm{D}$

IDH_mutation_status

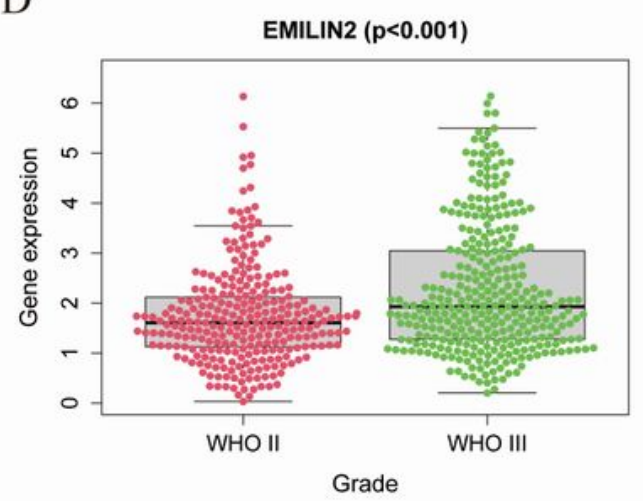

E
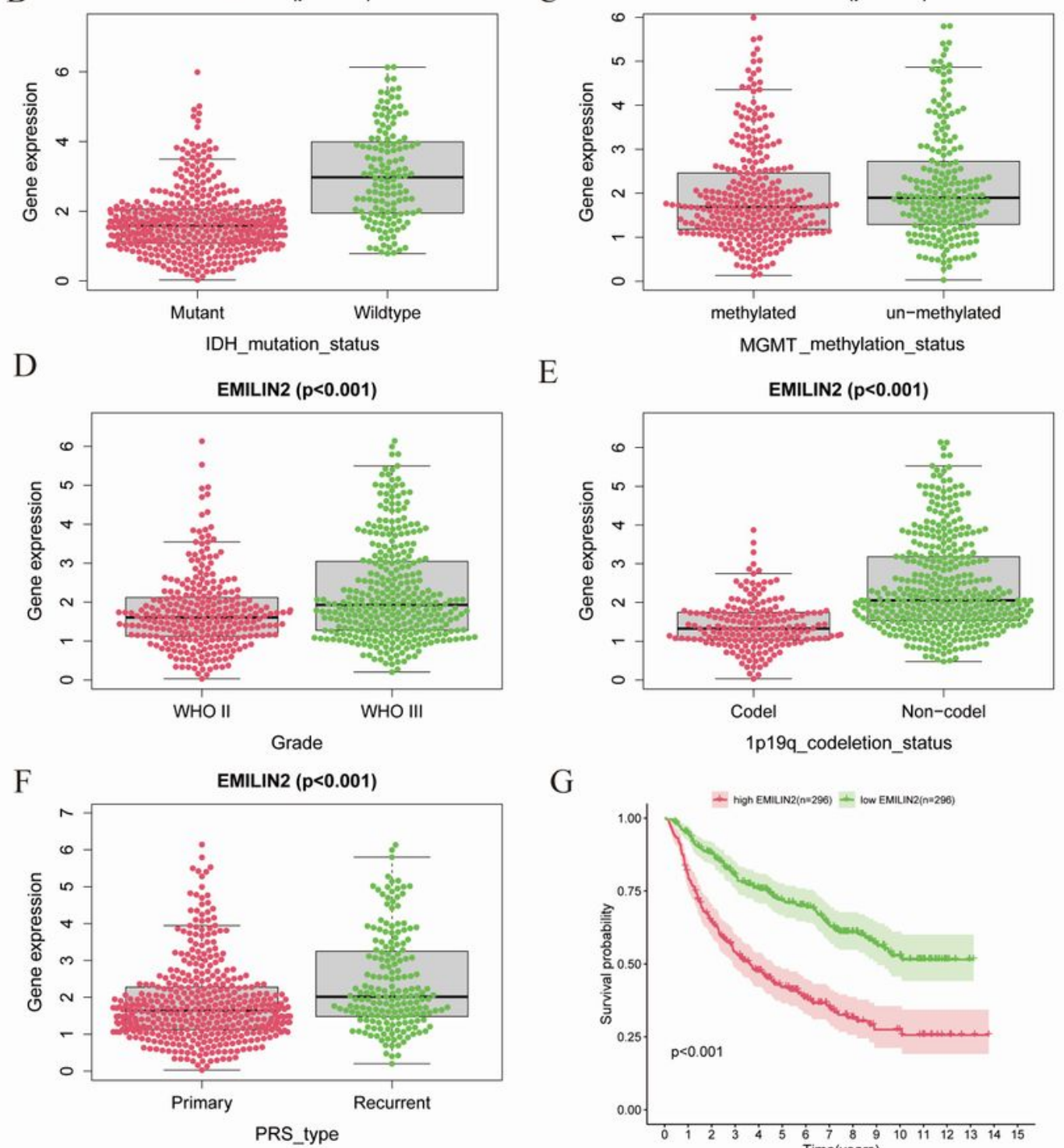

G

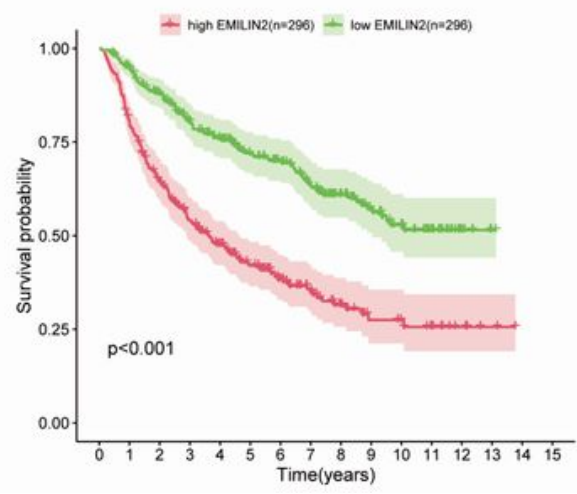

\section{Figure 3}

The expression value of EMILIN2 in different clinical features ( $(A)$ Histology $(P<0.001)$, (B)IDH-mutation $(P<0.001)$, (C) MGMT-methylation ( $P=0.045)$, (D)WHO grade $(P<0.001),(E) 1 p 19 q-c o d e l e t i o n(P<0.001)$, (F)primary and recurrent status $(P<0.001)$ ) and prognostic significance $(G)$ of EMILIN2 in LGG from CGGA $(P<0.001)$. 
A

$\begin{array}{lrr} & \text { pvalue } & \begin{array}{r}\text { Hazard ratio } \\ \text { EMILIN2 }\end{array} \\ <0.001 & 1.496(1.375-1.627) \\ \text { PRS_type } & <0.001 & 2.850(2.248-3.615) \\ \text { Histology } & <0.001 & 0.905(0.860-0.952) \\ \text { Grade } & <0.001 & 2.866(2.221-3.697) \\ \text { Gender } & 0.356 & 0.896(0.710-1.131) \\ \text { AGE } & 0.001 & 1.512(1.180-1.937) \\ \text { Radio } & 0.957 & 1.008(0.754-1.347) \\ \text { Chemo } & 0.063 & 1.271(0.987-1.638) \\ \text { IDH_mutation } & <0.001 & 0.440(0.342-0.567) \\ \text { 1p19q_codeletion } & <0.001 & 0.276(0.200-0.379) \\ \text { MGMTp_methylation } 0.083 & 0.800(0.622-1.030)\end{array}$

C

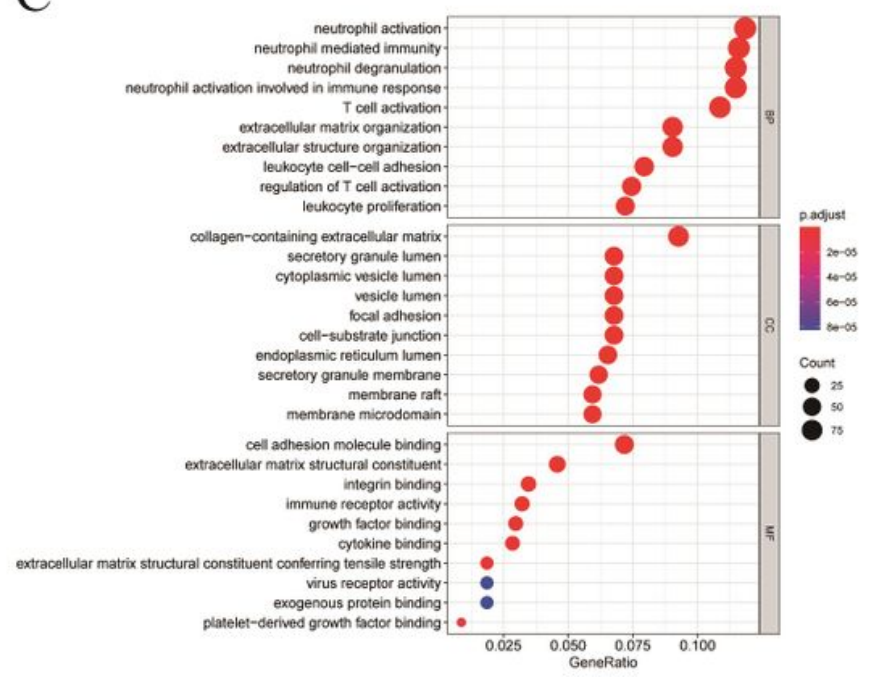

B
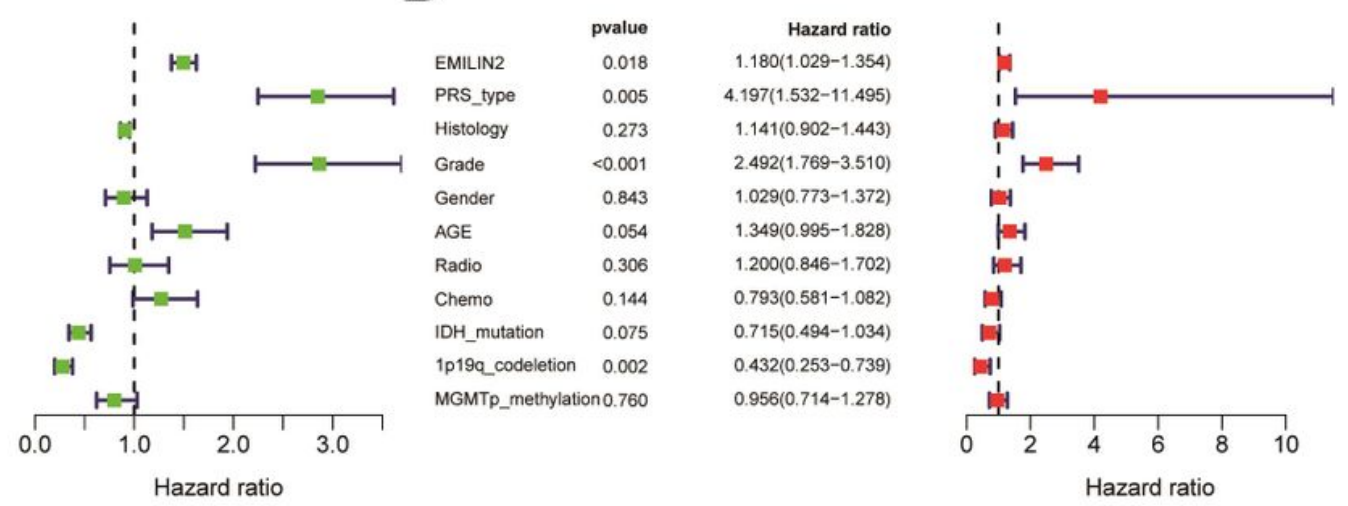

D

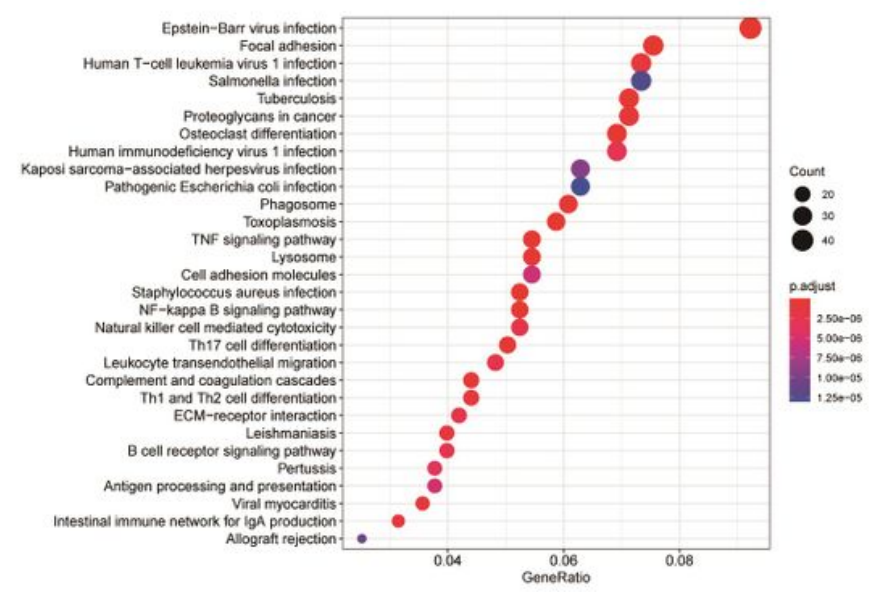

Figure 4

The univariate and multivariate Cox regression in LGG from CGGA and the GO and KEGG analysis among EMILIN2 related genes. (A) univariate Cox regression showed the EMILIN2, PRS, Histology, grade, age, IDH-mutation and 1p19q-codeletion were related to OS $(P<0.05)$. (B) multivariate Cox regression in CGGA showed the EMILIN2 could be an independent prognostic marker. 
A
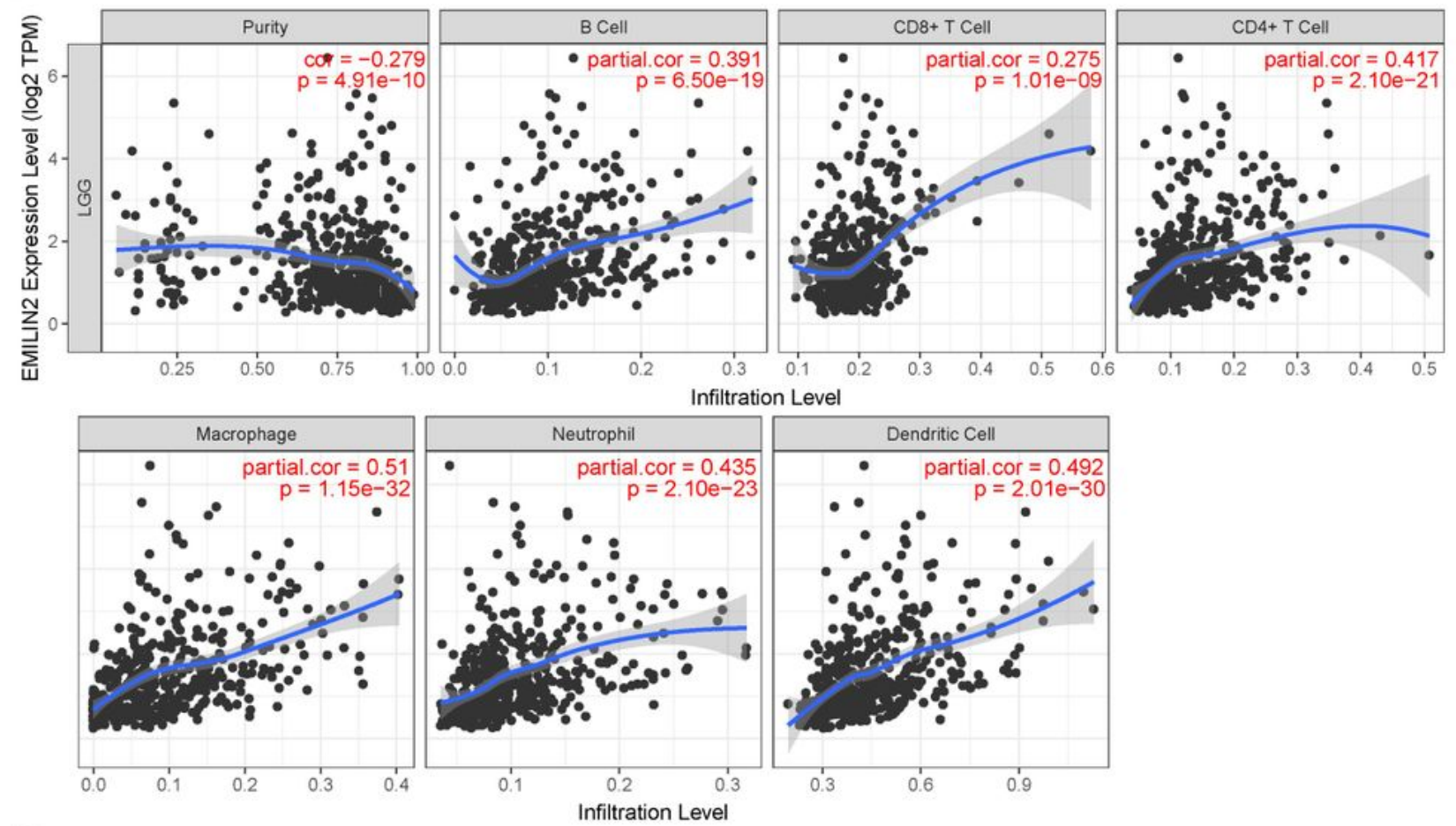

B
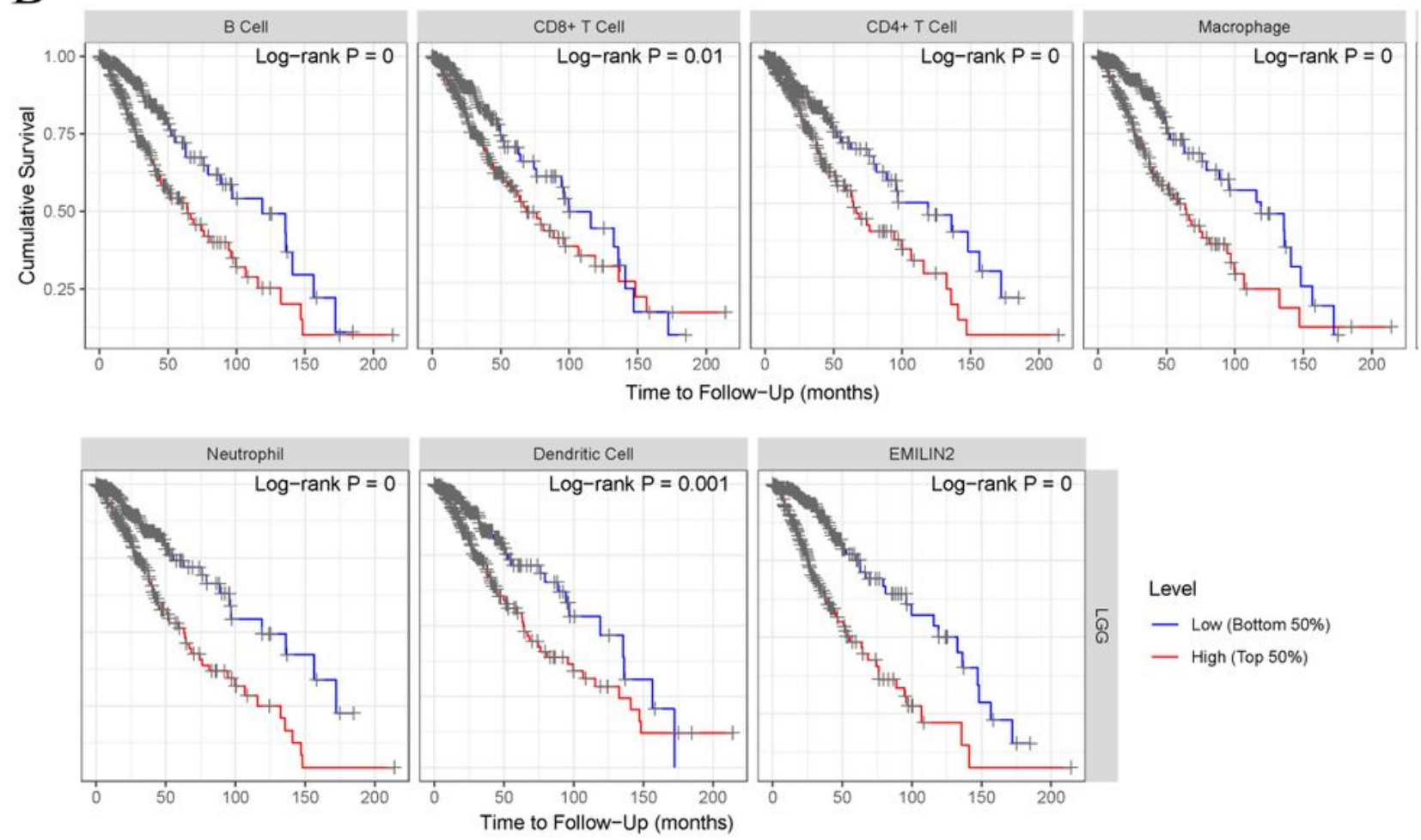

\section{Figure 5}

The Correlation of EMILIN2 expression with immune infiltration level in LGG. (A) EMILIN2 expression is positively correlated with $B$ cell, CD8 $+T$ cell, CD4+ T cell, dendritic cell, macrophage and neutrophil infiltration and was negatively correlated with tumour purity. (B) High-expressed EMILIN2 was significantly associated with the bad prognosis, as shown in Figure 5 , in different abundances of immune cells 